\title{
Childhood adversities and post-traumatic stress disorder: evidence for stress sensitisation in the World Mental Health Surveys*
}

Katie A. McLaughlin, Karestan C. Koenen, Evelyn J. Bromet, Elie G. Karam, Howard Liu, Maria Petukhova, Ayelet Meron Ruscio, Nancy A. Sampson, Dan J. Stein, Sergio Aguilar-Gaxiola, Jordi Alonso, Guilherme Borges, Koen Demyttenaere, Rumyana V. Dinolova, Finola Ferry, Silvia Florescu, Giovanni de Girolamo, Oye Gureje, Norito Kawakami, Sing Lee, Fernando Navarro-Mateu, Marina Piazza, Beth-Ellen Pennell, José Posada-Villa, Margreet ten Have, Maria Carmen Viana and Ronald C. Kessler

\section{Background}

Although childhood adversities are known to predict increased risk of post-traumatic stress disorder (PTSD) after traumatic experiences, it is unclear whether this association varies by childhood adversity or traumatic experience types or by age.

\section{Aims}

To examine variation in associations of childhood adversities with PTSD according to childhood adversity types, traumatic experience types and life-course stage.

\section{Method}

Epidemiological data were analysed from the World Mental Health Surveys $(n=27017)$.

\section{Results}

Four childhood adversities (physical and sexual abuse, neglect, parent psychopathology) were associated with similarly increased odds of PTSD following traumatic experiences (odds ratio $(O R)=1.8$, whereas the other eight childhood adversities assessed did not predict PTSD. Childhood adversity-PTSD associations did not vary across traumatic experience types, but were stronger in childhood-adolescence and earlymiddle adulthood than later adulthood.

\section{Conclusions}

Childhood adversities are differentially associated with PTSD, with the strongest associations in childhood-adolescence and early-middle adulthood. Consistency of associations across traumatic experience types suggests that childhood adversities are associated with generalised vulnerability to PTSD following traumatic experiences.

\section{Declaration of interest}

In the past 3 years, R.C.K. received support for his epidemiological studies from Sanofi Aventis; was a consultant for Johnson \& Johnson Wellness and Prevention, Shire, Takeda; and served on an advisory board for the Johnson \& Johnson Services Inc Lake Nona Life Project. R.C.K. is a co-owner of DataStat Inc, a market research firm that carries out healthcare research. In the past 3 years, K.D. has received personal fees from Lundbeck, Servier and Johnson \& Johnson. In the past 3 years, D.J.S. has received research grants and/or consultancy honoraria from AMBRF/The Foundation for Alcohol Research, Biocodex, Cipla, Lundbeck, National Responsible Gambling Foundation, Novartis, Servier and Sun. In the past 3 years, N.K. has received support (in the form of consultancy fees, lecture fees and royalties) from Aishin-Seiki, EAP Consulting, Igaku-Shoin, Japan Dental Association, Japan Housing Finance Agency, Japan Productivity Center, Junpukai Health Care Center, Meiji, Nanko-do, Nanzan-do, Occupational Health Foundation, Osaka Chamber of Commerce and Industry, Otsuka and Sekisui Chemicals, PHP Publication and Taishu-kan. He has received research grants from Infocom Ltd, Japan Management Association, Japanese Ministry of Education, Science, and Technology, Japanese Ministry of Health, Labor and Welfare and SoftBank Corp. Fujitsu Software Technologies Ltd has provided support to N.K. in the form of grants and royalties.

\section{Copyright and usage}

(c) The Royal College of Psychiatrists 2017.
Child maltreatment has repeatedly been shown to predict posttraumatic stress disorder (PTSD) among adults exposed to traumatic events. ${ }^{1-5}$ It is unknown whether or not a broader set of childhood adversities are similarly associated with increased vulnerability to PTSD following traumatic experiences, ${ }^{6}$ although the associations of more general stressful life events with anxiety, mood and substance disorders are known to be elevated among individuals who have experienced a wide range of childhood adversities. ${ }^{6-12}$ Prior work has documented that childhood adversities reflecting maladaptive family functioning (MFF) including child maltreatment, parent psychopathology and family violence - are more strongly associated with onset of mental disorders than other childhood adversities and that the joint

*The paper is submitted on behalf of the World Health Organization World Mental Health Survey collaborators - see the Appendix for details. associations of MFF childhood adversities with onset of mental disorders are subadditive (i.e. the incremental associations of additional childhood adversities decrease as the number of childhood adversities increases). ${ }^{13-16}$ Comparable analyses have not been carried out, though, with respect to the associations of childhood adversities with subsequent onset of PTSD in the wake of trauma exposure. It is also unclear whether childhood adversities are associated with a generalised vulnerability to PTSD following any trauma type or whether these associations are more pronounced for specific types of traumatic events. With regard to the latter possibility, it is known that PTSD risk varies markedly across traumatic event types ${ }^{17-19}$ and that prior exposure to some types of traumatic events, most notably those involving physical violence victimisation, are associated with elevated PTSD risk following subsequent traumatic events of the same type. ${ }^{19}$ It is plausible in light of this evidence to think that the associations 
of childhood adversities with PTSD might vary across trauma types. Finally, although childhood adversities have been shown to predict onset of anxiety, mood and substance disorders similarly at every stage of the lifespan, ${ }^{13-16}$ prior work has not examined whether vulnerability to PTSD among those with a history of childhood adversities varies according to life-course stage.

In the current study, we analyse the general population epidemiological data in the World Health Organization (WHO) World Mental Health (WMH) Surveys, a cross-national series of community epidemiological surveys of the prevalence and correlates of common mental disorders, to examine whether childhood adversities are associated with increased risk of PTSD after exposure to traumatic events. The large sample size of the WMH Surveys allows us to consider variation in the associations of childhood adversities with PTSD as a function of type of childhood adversity, type of traumatic event and life-course stage.

\section{Method}

\section{Samples}

Data come from the $20 \mathrm{WMH}$ Surveys in 18 countries that assessed childhood adversities and used an expanded assessment of PTSD (described below) to examine PTSD associated with a randomly selected traumatic event (online Table DS1). These surveys included ten in countries classified by the World Bank ${ }^{20}$ as high income (national surveys in Belgium, France, Germany, Italy, The Netherlands, Northern Ireland, Spain and the USA along with a survey of metropolitan areas in Japan and the Murcia region of Spain), seven in countries classified as upper-middle income (national surveys in Bulgaria, Lebanon, Romania and South Africa along with a survey of all non-rural areas in Mexico and regional surveys in São Paulo, Brazil and Medellin, Colombia), and three in countries classified as lower-middle/low income (national surveys in Peru and Ukraine and a survey of all non-rural areas in Colombia). The two Colombia surveys were classified as being in different country-income groups because the World Bank ranking of Colombia's income level changed between the times of the two surveys. All surveys were based on multistage clustered area probability samples of adult household residents. Response rates ranged from $45.9 \%$ (France) to $97.2 \%$ (Colombia) and had a weighted mean of $70.9 \%$ across surveys. A detailed description of sampling procedures is presented elsewhere. ${ }^{21}$ All procedures contributing to this work comply with the ethical standards of the relevant national and institutional committees on human experimentation and with the Helsinki Declaration of 1975, as revised in 2008 .

\section{Field procedures}

Interviews were administered face to face in respondent's homes after obtaining informed consent using procedures approved by local institutional review boards. The interview schedule was developed in English and translated into other languages using a standardised WHO translation, back-translation and harmonisation protocol. ${ }^{22}$ Training and field procedures were supervised by the WMH data collection coordination centre to guarantee cross-national consistency. ${ }^{22}$

Interviews were administered in two parts. Part I, administered to all respondents, assessed core DSM-IV ${ }^{23}$ mental disorders $(n=83805)$. Part II was administered to all respondents who met lifetime criteria for any Part I disorder and a probability subsample of other Part I respondents $(n=42430)$. Part II assessed additional disorders and correlates. Questions about traumatic experiences and PTSD were included in Part II. Part II respondents were weighted to adjust for differential probabilities of selection and deviations between the sample and population demographic-geographic distributions. Details about WMH weighting are presented elsewhere. ${ }^{21}$ The subsample of Part II respondents who reported lifetime exposure to one or more traumatic events $(n=27017)$ is the focus of the current report.

\section{Measures}

\section{Exposure to traumatic events}

Part II respondents were asked about lifetime exposure to 27 different types of traumatic events in addition to two open-ended questions about exposure to 'any other' traumatic event and to any 'private' traumatic events the respondent did not want to discuss. Positive responses were followed by probes to assess number of lifetime exposures and age at first exposure to each traumatic event type. Exploratory factor analysis in the WMH sample found six traumatic experience groups: ${ }^{24}$ five reflecting exposure to organised violence (such as civilian in a war zone, relief worker in a war zone, refugee); five related to participation in organised violence (such as combat experience, witnessed atrocities); three reflecting physical violence victimisation (witnessed violence at home as a child; beaten by a caregiver as a child; victim of assault); seven related to sexual violence (such as raped, sexually assaulted, beaten by a romantic partner); six involving accidents/injuries (such as natural disaster, toxic chemical exposure, motor vehicle accident); and three that were not strongly correlated with any other traumatic experiences (mugged or threatened with a weapon, man-made disaster other than chemical exposure, unexpected death of a loved one).

\section{PTSD}

Mental disorders were assessed with the Composite International Diagnostic Interview (CIDI), ${ }^{25}$ a fully structured interview administered by trained lay interviewers that assesses DSM-IV disorders. PTSD was assessed in relation to the lifetime traumatic event the respondent identified as 'worst' (i.e. as causing the most severe-persistent core symptoms of PTSD) and in response to one randomly selected traumatic event out of all traumatic events the respondent reported experiencing. The random traumatic event could be the same as the traumatic event selected as the worst. Population estimates of PTSD prevalence and conditional risk of PTSD are likely overestimated when assessed in relation to a respondent's worst traumatic event. ${ }^{17,18}$ Consequently, we focus here on PTSD associated with randomly selected traumatic events, an approach that has previously been used in cross-national research from the WMH Surveys. ${ }^{19,26}$ To do so, we created a population-level representative sample of traumatic events. As each respondent had only one randomly selected traumatic event no matter how many lifetime traumatic events they experienced, traumatic events that occurred to respondents who experienced a high number of traumatic events were underrepresented. We corrected for this by weighting the randomly selected traumatic event by the inverse of its probability of selection and then multiplying this weight by the Part II weight to generate a sample representative of all traumatic events experienced by all respondents. These weighted data no longer represent the population of respondents but the population of all traumatic events experienced in the population. The consolidated weight was standardised in each survey to equal the number of respondents assessed for randomly selected traumatic events.

As detailed elsewhere, ${ }^{27}$ masked clinical reappraisal interviews with the Structured Clinical Interview for DSM-IV (SCID) conducted in four WMH countries found CIDI-SCID concordance for DSM-IV PTSD to be moderate (area under the curve 
$($ AUC $)=0.69)$. Sensitivity and specificity were 0.38 and 0.99 , respectively, resulting in a likelihood ratio positive $(\mathrm{LR}+)$ of 42.0 , which is well above the threshold of 10 typically used to consider screening scale diagnoses definitive. ${ }^{28}$ Consistent with the high LR+, the proportion of CIDI cases confirmed by the SCID was $86.1 \%$. This means that the vast majority of CIDI/DSM-IV PTSD cases would be diagnosed with PTSD by a trained clinician.

\section{Childhood adversities}

Twelve childhood adversities occurring before age 18 years were assessed. These included three types of interpersonal loss (parental death, parental divorce and other loss of contact with parents/ caregivers), four types of parental maladjustment (psychopathology, substance misuse, criminality and family violence), three types of maltreatment (physical abuse, sexual abuse, neglect), respondent serious physical illness and economic adversity. These childhood adversities align with the Adverse Childhood Experiences Study, ${ }^{29}$ although we did not assess emotional abuse and additionally assessed economic adversity and serious physical illness.

Physical abuse of the respondent by caregivers was assessed with a modified version of the Conflict Tactics Scale (CTS) ${ }^{30}$ and with an item from the traumatic event section of the CIDI. Sexual abuse was assessed with questions from the CIDI regarding sexual assault, attempted rape and rape. Neglect was assessed with questions that assessed frequency of not having adequate food, clothing or medical care, having inadequate supervision and being required to do chores that were age-inappropriate. ${ }^{31}$

Parental criminality assessed whether a parent engaged in criminal activities or was ever arrested or sent to prison. Parent psychopathology (major depression, generalised anxiety disorder, panic disorder, suicide attempt) and substance misuse were assessed with a revised version of the Family History Research Diagnostic Criteria Interview. ${ }^{32,33}$ Family violence was assessed with the modified CTS and an item in the traumatic event section of the CIDI. Economic adversity was assessed with questions about whether the respondent's family received welfare or other government assistance or often did not have enough money to pay for basic necessities. Physical illness was assessed with a standard chronic conditions checklist.

Four of these childhood adversities are also traumatic experiences: sexual abuse, physical abuse, witnessing family violence during childhood, and childhood physical illness. If the randomly selected traumatic experience was one of these four childhood adversities, it was not included among the childhood adversity measures. Several WMH countries omitted some childhood adversities (neglect in South Africa; parental divorce and neglect in the six Western European countries). Rather than exclude these countries or exclude the missing childhood adversities from analysis, we imputed individual-level missing values using multiple imputation. ${ }^{34}$

Prior factor analysis in this sample identified a cluster of highly correlated childhood adversities reflecting MFF that included parent psychopathology, parent substance misuse, parent criminality, family violence, physical abuse, sexual abuse and neglect. ${ }^{13}$ We analysed these MFF childhood adversities separately from other childhood adversities (parental death and divorce, other parental loss, physical illness, economic adversity), which exhibit weaker intercorrelations.

\section{Analysis methods}

Cross-tabulations were used in this weighted-standardised dataset to estimate prevalence of exposure to childhood adversities associated with randomly selected traumatic events. Associations of these childhood adversities with PTSD in the full sample of randomly selected traumatic events were then estimated using logistic regression models controlling gender, age, traumatic event type and history of prior traumatic events of the same type as the randomly selected traumatic experience for traumatic events where our previous work shows that prior exposure significantly predicts PTSD risk. ${ }^{19}$ Dummy predictor variables were included for survey to adjust for between-survey differences in aggregate PTSD prevalence. A series of multivariate models was then estimated using a modelling approach we have employed previously ${ }^{13,15,16}$ that distinguishes between MFF and other childhood adversities and evaluates separate and joint associations of multivariate childhood adversity profiles with PTSD onset after traumatic event exposure. We began with a series of bivariate models (M1) examining each childhood adversity separately. We then estimated an additive multivariate model that included a separate predictor variable for each of the 12 childhood adversities (M2) followed by a model that included predictor variables for number of childhood adversities without variables for specific childhood adversity types (M3). The latter model included one variable for the number of MFF childhood adversities (range: $0-4)$ and two dummy variables indicating exposure to exactly 1 or $2+$ other childhood adversities. Only MFF childhood adversities that were significant in the bivariate models were included in the 0-4 count. We then estimated a model that included dummy variables for childhood adversity types in addition to variables for number of MFF and other childhood adversities (M4). The next model deleted the four MFF childhood adversity type variables that were included in the MFF childhood adversity count variable but retained the other type variables (M5). The next model (M6) included the same childhood adversity type variables as M5 but included dummy variables for the exact numbers of MFF childhood adversities rather than the count variable. A final model (M7) included only the MFF childhood adversity count variable and dropped all other childhood adversity variables.

Inspection of mean-squared error and area under the receiver operating characteristic curve (AUC) based on replicated tenfold cross-validation with ten replications was used to select the best multivariate model among M2-M7 to predict PTSD in response to the randomly selected traumatic event. Additional models examined whether associations of childhood adversities with PTSD varied by traumatic event type and timing of trauma exposure with interaction terms added to the best-fitting model. Composite traumatic event measures used in these interactions were based on prior analysis showing that odds of PTSD in response to the randomly selected traumatic event were equivalent for all but eight trauma event types. ${ }^{19}$ Here, we included predictor variables for those eight trauma types and one variable for all other trauma types. Given that all respondents were exposed to one randomly selected traumatic event, the indeterminacy of the solution created by including an odds ratio (OR) for each trauma type was resolved by scaling the product of all traumaspecific ORs to 1.0. Any trauma-specific ORs significantly different from 1.0 can be interpreted as having significantly higher- or lower-than-average odds of PTSD; each traumatic event type was given equal weight in computing this average. Interactions between childhood adversities and age of exposure to the randomly selected traumatic event classified age into five groups $(0-12,13-24,25-44,45-59$, and $60+$ years).

Logistic regression coefficients and standard errors were exponentiated and are reported as ORs with 95\% confidence intervals. Statistical significance was evaluated using 0.05 -level two-sided tests based on the design-based Taylor series method ${ }^{35}$ implemented in the SAS software system (version 9.2) to adjust for the weighting and clustering of observations. 


\section{Results}

\section{Childhood adversity prevalence}

Prevalence estimates of childhood adversities associated with representative traumatic events are shown in Table 1 . The proportions of traumatic events occurring to individuals with a history of childhood adversities range from 3.8\% (sexual abuse) to $20.9 \%$ (physical abuse). It is noteworthy that all prevalence estimates in the sample of traumatic events are higher than in the sample of respondents, indicating that childhood adversities are positively associated with number of traumatic events experienced. For example, $10.7 \%$ of respondents reported exposure to physical abuse, but $20.9 \%$ of all traumatic events occurred to individuals exposed to physical abuse. The most elevated childhood adversity prevalence estimates in the traumatic event sample relative to the sample of respondents involve the MFF childhood adversities of family violence, physical abuse and sexual abuse.

\section{Associations of childhood adversities with PTSD}

In bivariate models (M1) that considered one childhood adversity at a time, only MFF childhood adversities were significant predictors of PTSD after the randomly selected traumatic event, with ORs in the range of 1.6-2.2 (Table 2). MFF childhood adversities associated with PTSD included physical and sexual abuse, neglect and parent psychopathology. The ORs for incremental associations of these four MFF childhood adversities with PTSD were lower in the additive multivariate model (M2) that included all childhood adversity types. Three of the four MFF childhood adversities remained significant in that model (parent psychopathology, sexual abuse, neglect), with ORs in the range of 1.8-2.0. MFF childhood adversities, as a set, were significantly associated with PTSD in M2 $\left(\chi_{(7)}^{2}=40.8\right.$, $P<0.001)$, but other childhood adversities were not $\left(\chi^{2}{ }_{(5)}=5.8\right.$, $P=0.33$ ). In addition, the strength of the ORs varied significantly across the different types of MFF childhood adversities $\left(\chi_{(6)}^{2}=18.5, P=0.005\right)$ but not other childhood adversities $\left(\chi^{2}(4)=5.8, P=0.22\right)$.

In multivariate model $\mathrm{M} 3$, which considered only number and not type of childhood adversities, the number of MFF childhood adversities was significantly associated with PTSD (OR $=1.7$, $P<0.001)$, but the number of other childhood adversities was not $\left(\chi_{(2)}^{2}=0.4, P=0.84\right)$. (Table 2).

Subsequent models (M4-M6) included information about both type and number of childhood adversities. We examined models including variables for number of MFF and other childhood adversities as well as type variables for all childhood adversities (M4), and type variables for childhood adversities excluding the four MFF childhood adversities included in the count variable (M5). We also examined a model that included variables for exactly 1,2,3 and $4 \mathrm{MFF}$ childhood adversities rather than the $0-4$ count (M6). However, the best-fitting model (M7) included only the count variable for the four individually significant MFF childhood adversities (Table 2). Consistent with M7 being the best model, neither the other MFF childhood adversities not included in the count variable nor other childhood adversities were associated with PTSD in M5 or M6, indicating an absence of meaningful associations of childhood adversities other than physical and sexual abuse, neglect and parent psychopathology with PTSD (Table 2). In the best-fitting model (M7), number of MFF childhood adversities was significantly associated with PTSD $(\mathrm{OR}=1.8, P<0.001)$.

\begin{tabular}{|c|c|c|}
\hline & \multicolumn{2}{|c|}{$\%$ (s.e.) } \\
\hline & $\begin{array}{l}\text { Proportion of } \\
\text { traumatic experiences } \\
\text { occurring to } \\
\text { respondents with a } \\
\text { history of each } \\
\text { childhood adversity }\end{array}$ & $\begin{array}{l}\text { Proportion of } \\
\text { respondents } \\
\text { with a history of } \\
\text { each childhood } \\
\text { adversity }\end{array}$ \\
\hline \multicolumn{3}{|l|}{$\begin{array}{l}\text { Maladaptive family functioning } \\
\text { childhood adversities }\end{array}$} \\
\hline Parent psychopathology & $13.7(0.6)$ & $9.5(0.3)$ \\
\hline Parent substance misuse & $7.8(0.4)$ & $6.0(0.2)$ \\
\hline Parent criminality & $6.5(0.4)$ & $4.0(0.2)$ \\
\hline Family violence & $16.3(0.6)$ & $9.7(0.3)$ \\
\hline Physical abuse & $20.9(0.7)$ & $10.7(0.3)$ \\
\hline Sexual abuse & $3.8(0.2)$ & $1.9(0.1)$ \\
\hline Neglect & $8.2(0.3)$ & $5.7(0.2)$ \\
\hline \multicolumn{3}{|l|}{ Other childhood adversities } \\
\hline Parent death & $14.4(0.5)$ & $13.3(0.3)$ \\
\hline Parent divorce & $9.7(0.5)$ & $8.0(0.3)$ \\
\hline Other parent loss & $7.7(0.4)$ & $6.0(0.2)$ \\
\hline Serious physical illness & $6.3(0.4)$ & $3.5(0.2)$ \\
\hline Economic adversity & $6.1(0.3)$ & $4.7(0.2)$ \\
\hline \multicolumn{3}{|c|}{$\begin{array}{l}\text { a. Given that randomly selected traumatic events were weighted by the inverse } \\
\text { of their probabilities of selection and then multiplied by the Part II weight, the } \\
\text { weighted sample of traumatic events represents the population of all traumatic } \\
\text { events experienced in the population. } \\
\text { b. Prevalence of childhood adversities among the } 27017 \text { respondents included in the } \\
\text { analysis. }\end{array}$} \\
\hline
\end{tabular}

\section{Differential associations by trauma event type and timing of trauma exposure}

To determine whether the association of number of MFF childhood adversities with PTSD varied as a function of the type of traumatic event, we added interactions between this variable and nine indicators for trauma type to the best-fitting childhood adversity model (M7). The association of number of MFF childhood adversities with PTSD did not vary across traumatic event types $\left(\chi_{(8)}^{2}=13.9, P=0.08\right)$. The ORs for the interaction term were in the range of $0.8-1.6$ with the exception of natural disaster $(\mathrm{OR}=0.3)$, witnessing atrocities $(\mathrm{OR}=0.4)$ and being kidnapped $(\mathrm{OR}=3.1)$ (Table 3).

Next, we examined interactions between number of MFF childhood adversities and timing of trauma exposure. Here, the association of number of MFF childhood adversities with PTSD varied depending on age of trauma exposure $\left(\chi_{(4)}^{2}=16.4\right.$, $P=0.002)$. Specifically, coefficients were positive and associations were significant for traumatic events occurring during childhood $(\mathrm{OR}=1.6, P=0.007)$, adolescence $(\mathrm{OR}=1.8, P=0.001)$, and adulthood through age $44(\mathrm{OR}=1.9, P<0.001)$ but not for traumatic events occurring in later-middle age (ages 45-59, OR $=1.5$, $P=0.16)$, and the $\mathrm{OR}$ was reversed among respondents aged $60+(\mathrm{OR}=0.1, P<0.001)$.

\section{Discussion}

We found that exposure to some, but not all, types of childhood adversities is associated with increased likelihood of developing PTSD. Of the wide range of childhood adversities examined, only physical and sexual abuse, neglect and parent psychopathology were associated with elevated risk of developing PTSD following a traumatic event. These findings extend prior work documenting higher prevalence of past-year PTSD following a past-year traumatic event among individuals with high levels of 
Table 2 Multivariate associations (odds ratios) between childhood adversities and post-traumatic stress disorder (PTSD) in response to a randomly selected traumatic event in the World Health Organization World Mental Health Surveys $(n=27017)^{\text {a,b }}$

\begin{tabular}{|c|c|c|c|c|c|c|c|}
\hline & M1 & M2 & M3 & M4 & M5 & M6 & M7 \\
\hline \multicolumn{8}{|l|}{ MFF childhood adversities } \\
\hline $\begin{array}{l}\text { Parent psychopathology, } \\
\text { OR }(95 \% \mathrm{Cl})\end{array}$ & $2.2^{*}(1.6-3.0)$ & $2.0 *(1.5-2.7)$ & - & - & - & - & - \\
\hline $\begin{array}{l}\text { Parent substance misuse, } \\
\text { OR }(95 \% \mathrm{Cl})\end{array}$ & $1.2(0.9-1.7)$ & $0.9(0.6-1.3)$ & - & $0.9(0.6-1.3)$ & $0.9(0.6-1.3)$ & $0.9(0.6-1.3)$ & - \\
\hline Parent criminality, OR ( $95 \%$ Cl) & $1.4(0.9-2.3)$ & $1.1(0.7-1.9)$ & - & $1.1(0.7-1.9)$ & $1.1(0.7-1.9)$ & $1.1(0.7-1.9)$ & - \\
\hline Family violence, OR (95\% Cl) & $1.1(0.7-1.7)$ & $1.0(0.6-1.5)$ & - & $1.0(0.6-1.5)$ & $1.1(0.7-1.7)$ & $1.1(0.7-1.7)$ & - \\
\hline Physical abuse, OR (95\% Cl) & $1.6^{*}(1.1-2.3)$ & $1.3(0.9-2.0)$ & - & $0.7(0.4-1.1)$ & - & - & - \\
\hline Sexual abuse, OR $(95 \% \mathrm{Cl})$ & $2.0 *(1.2-3.4)$ & $1.8 *(1.1-3.0)$ & - & $0.9(0.5-1.5)$ & - & - & - \\
\hline Neglect, OR $(95 \% \mathrm{Cl})$ & $2.2^{*}(1.4-3.2)$ & $1.9 *(1.2-2.8)$ & - & $0.9(0.6-1.5)$ & - & - & - \\
\hline$\chi_{(7)}^{2}$ & - & $40.8^{*}$ & - & - & - & - & - \\
\hline$\chi_{(6)}^{2}$ & - & $18.5^{\star}$ & - & 3.4 & - & - & - \\
\hline$\chi^{2}(3)$ & - & - & - & - & 0.3 & 0.3 & - \\
\hline \multicolumn{8}{|l|}{ Other childhood adversities } \\
\hline Parent death, OR $(95 \% \mathrm{Cl})$ & $1.4(0.9-2.4)$ & $1.4(0.8-2.3)$ & - & $1.4(0.8-2.4)$ & $1.4(0.7-2.4)$ & $1.4(0.7-2.4)$ & - \\
\hline Parent divorce, OR $(95 \% \mathrm{Cl})$ & $0.9(0.6-1.2)$ & $0.9(0.6-1.2)$ & - & $0.9(0.6-1.3)$ & $0.8(0.6-1.3)$ & $0.9(0.6-1.3)$ & - \\
\hline Other parent loss, OR $(95 \% \mathrm{Cl})$ & $0.9(0.6-1.4)$ & $0.8(0.5-1.2)$ & - & $0.7(0.4-1.3)$ & $0.7(0.4-1.3)$ & $0.7(0.4-1.3)$ & - \\
\hline Serious physical illness, OR $(95 \% \mathrm{Cl})$ & $1.1(0.8-1.7)$ & $1.0(0.7-1.5)$ & - & $1.0(0.7-1.6)$ & $1.0(0.6-1.6)$ & $1.0(0.7-1.6)$ & - \\
\hline Economic adversity, OR $(95 \% \mathrm{Cl})$ & $1.3(0.8-2.0)$ & $1.2(0.7-1.8)$ & - & $1.1(0.6-1.9)$ & $1.1(0.6-2.0)$ & $1.1(0.6-2.0)$ & - \\
\hline$\chi_{(5)}^{2}$ & - & 5.8 & - & 6.1 & 6.7 & 6.8 & - \\
\hline$\chi^{2}(4)$ & - & 5.8 & - & 5.8 & 6.3 & 6.4 & - \\
\hline$\chi^{2}(12)$ & - & $63.8^{\star}$ & - & 9.3 & 6.9 & 6.9 & - \\
\hline \multicolumn{8}{|l|}{ Number of MFF childhood adversities } \\
\hline $0-4,{ }^{c}$ OR $(95 \% \mathrm{Cl})$ & - & - & $1.7^{*}(1.5-2.1)$ & $2.0 *(1.5-2.7)$ & $1.8^{*}(1.5-2.1)$ & - & $1.8^{*}(1.5-2.1)$ \\
\hline 1, OR $(95 \% \mathrm{Cl})$ & - & - & - & - & - & $1.6^{*}(1.1-2.2)$ & - \\
\hline 2, OR $(95 \% \mathrm{Cl})$ & - & - & - & - & - & $2.8^{*}(1.8-4.4)$ & - \\
\hline $3, \mathrm{OR}(95 \% \mathrm{Cl})$ & - & - & - & - & - & $5.4^{*}(2.7-10.6)$ & - \\
\hline 4, OR $(95 \% \mathrm{Cl})$ & - & - & - & - & - & $13.7^{*}(3.6-51.4)$ & - \\
\hline$\chi^{2}(4)$ & - & - & - & - & - & $36.3^{*}$ & - \\
\hline$\chi^{2}(3)$ & - & - & - & - & - & $19.6^{*}$ & - \\
\hline \multicolumn{8}{|l|}{ Number of other childhood adversities } \\
\hline 1, OR $(95 \% \mathrm{Cl})$ & - & - & $1.1(0.7-1.6)$ & - & - & - & - \\
\hline $2+, \mathrm{OR}(95 \% \mathrm{Cl})$ & - & - & $1.1(0.8-1.7)$ & $1.1(0.6-2.1)$ & $1.1(0.6-2.2)$ & $1.1(0.6-2.2)$ & - \\
\hline$\chi^{2}(2)$ & & - & 0.4 & - & - & - & \\
\hline Mean-squared error ${ }^{d}$ & - & 0.039214 & 0.039162 & 0.039232 & 0.039206 & 0.039278 & 0.039146 \\
\hline$A \cup C^{d}$ & - & 0.738 & 0.741 & 0.737 & 0.737 & 0.734 & 0.743 \\
\hline \multicolumn{8}{|c|}{$\begin{array}{l}\text { MFF, maladaptive family functioning; OR, odds ratio; AUC, area under the receiver operating characteristic curve. } \\
\text { a. Models were estimated using logistic regression with PTSD in response to a randomly selected traumatic event as the outcome variable. Each model controlled for survey, } \\
\text { age, gender, nine dummy variables for trauma type and six dummy variables for prior exposure to the same trauma type for types shown in prior analysis to influence later risk of } \\
\text { PTSD in response to a traumatic experience of the same type (see Liu et al } \text { I }^{19} \text { for details). } \\
\text { b. Models were estimated as follows plus the controls noted in footnote a. M1, with one childhood adversity at a time; M2, with all } 12 \text { childhood adversities; M3, with dummy } \\
\text { variables for the number of childhood adversities without any information about childhood adversity type; M4, with dummy variables for both number and type of childhood } \\
\text { adversities; M5, with dummy variables for both number and type of childhood adversities, removing the variables for childhood adversity type for the four MFF childhood adversities } \\
\text { included in the 0-4 count variable (see footnote c); M6, with dummy variables for both number and type of childhood adversities, removing the variables for childhood adversity type } \\
\text { for the four MFF childhood adversities included in the } 0-4 \text { count variable (see footnote c), and with number of MFF CAs estimated as a 0-4 count variable; M7, with the } 0-4 \text { MFF CA } \\
\text { count variable (see footnote c). } \\
\text { c. The } 0-4 \text { variable is a count of the number of the following childhood adversities experienced by the respondent: physical abuse, sexual abuse, neglect and parent psychopathology. } \\
\text { d. These measures are based on replicated tenfold cross-validation with ten replications. } \\
\text { *Significant at the } 0.05 \text { level, two-sided test. }\end{array}$} \\
\hline
\end{tabular}

childhood adversity exposure ${ }^{6}$ and greater risk of developing PTSD among individuals who were maltreated as children ${ }^{1-5}$ by documenting parental psychopathology as a childhood adversity associated with PTSD in addition to maltreatment and by documenting that these vulnerabilities do not extend to the other childhood adversity types considered here. Our finding of an association of parental psychopathology with PTSD is broadly consistent with evidence that parent psychopathology has robust but largely non-specific associations with offspring psychopathology. ${ }^{36,37}$ Unlike prior work suggesting that the associations of childhood adversities with mental disorders are subadditive, such that the incremental effects of additional childhood adversities get relatively smaller as the number of childhood adversities increases, ${ }^{14-16}$ our results indicate that the associations of childhood adversities involving maltreatment and parent psychopathology with PTSD are additive. That is, each additional exposure to these specific childhood adversities is associated with increased odds of developing PTSD following a traumatic event that is relatively consistent as the number of childhood adversities increases.

The association of childhood adversities involving child maltreatment and parent psychopathology with PTSD did not vary across a wide range of trauma types. This is surprising, given extensive previous research showing that conditional risk of PTSD varies considerably across traumatic event types. ${ }^{17-19}$ Prior work on stress sensitisation has produced conflicting findings in terms of whether vulnerability to stressors among individuals with a history of childhood adversities is general or specific to certain types of stressors. Some studies have shown that relatively mild stressors are more likely to trigger depression among those with a history of childhood adversity than those without, ${ }^{10,38}$ whereas other work indicates that childhood adversity exposure magnifies the association between relatively severe stressors and psychopathology. ${ }^{6}$ Our failure to document variation in the associations 


\begin{tabular}{|c|c|c|}
\hline & $\begin{array}{c}\text { Variation by trauma } \\
\text { type, }{ }^{\text {b }} \mathrm{M} 8\end{array}$ & $\begin{array}{c}\text { Variation by age at trauma } \\
\text { exposure, }{ }^{\mathrm{C}} \mathrm{M} 9\end{array}$ \\
\hline \multicolumn{3}{|c|}{ Interaction of number of MFF childhood adversities with trauma types } \\
\hline Civilian in a war zone, OR $(95 \% \mathrm{Cl})$ & $0.8(0.3-2.3)$ & - \\
\hline Civilian in a region of terror, OR $(95 \% \mathrm{Cl})$ & $1.1(0.6-2.0)$ & - \\
\hline Kidnapped, OR (95\% Cl) & $3.1 *(1.2-7.7)$ & - \\
\hline Witnessed death, OR $(95 \% \mathrm{Cl})$ & $1.6^{*}(1.0-2.6)$ & - \\
\hline Saw atrocities, OR $(95 \% \mathrm{Cl})$ & $0.4(0.1-1.6)$ & - \\
\hline Sexual violence, OR $(95 \% \mathrm{Cl})$ & $1.2(0.8-1.8)$ & - \\
\hline Natural disaster, OR (95\% Cl) & $0.3^{*}(0.1-0.9)$ & - \\
\hline Unexpected death of a loved one, OR $(95 \% \mathrm{Cl})$ & $1.4(0.9-2.3)$ & - \\
\hline All other traumatic experiences, OR $(95 \% \mathrm{Cl})$ & $1.2(0.8-1.7)$ & - \\
\hline$\chi^{2}(8)$ & 13.9 & \\
\hline \multicolumn{3}{|c|}{ Interaction of number of MFF childhood adversities with age at trauma exposure } \\
\hline $0-12$ years, OR $(95 \% \mathrm{Cl})$ & - & $1.6^{*}(1.1-2.3)$ \\
\hline 13-24 years, OR $(95 \% \mathrm{Cl})$ & - & $1.8 *(1.3-2.6)$ \\
\hline $25-44$ years, OR $(95 \% \mathrm{Cl})$ & - & $1.9 *(1.3-2.7)$ \\
\hline $45-59$ years, OR $(95 \% \mathrm{Cl})$ & - & $1.5(0.9-2.6)$ \\
\hline $60+, \mathrm{OR}(95 \% \mathrm{Cl})$ & - & $0.1 *(0.0-0.3)$ \\
\hline$\chi^{2}(4)$ & & $16.4^{\star}$ \\
\hline \multicolumn{3}{|c|}{$\begin{array}{l}\text { MFF, maladaptive family functioning; OR, odds ratio. } \\
\text { a. Models were estimated using logistic regression with PTSD in response to a randomly selected traumatic event as the outcome variable. Each model controlled for survey, age, } \\
\text { gender, nine dummy variables for trauma type and six dummy variables for prior exposure to the same trauma type for types shown in prior analysis to influence later risk of PTSD } \\
\text { in response to a traumatic event of the same type (see Liu et al19 for details). Childhood adversity and control variables are based on the best-fitting model of childhood adversities } \\
\text { in predicting PTSD in response to a randomly selected traumatic event (M7, Table } 2 \text { ). } \\
\text { b. The model included nine dummy variables for the interaction of the } 0-4 \text { MFF childhood adversity count variable with trauma types in addition to childhood adversity and control } \\
\text { variables from M7, Table } 2 \text {. Trauma types are based on prior factor analysis in this sample (see Method section for details). } \\
\text { c. The model included five dummy variables for the interaction of the } 0-4 \text { MFF childhood adversity count variable with age at trauma exposure in addition to childhood adversity and } \\
\text { control variables from M7, Table } 2 \text {. } \\
\text { *Significant at the } 0.05 \text { level, two-sided test. }\end{array}$} \\
\hline
\end{tabular}

of childhood adversities with PTSD as a function of trauma type is consistent with the possibility that childhood adversities produce a generalised vulnerability to PTSD following traumatic events.

The associations of childhood adversities and PTSD varied by life-course stage, with the associations observable during childhood, adolescence and early-middle adulthood, but not during late-middle age or later adulthood. We are unaware of prior research examining this specification, although it is noteworthy that most prior studies documenting an interaction between childhood adversities and later stressors in predicting mental disorders focused on adolescence or young adulthood. ${ }^{10-12,38,39}$ There are two possible interpretations of this finding. The first is that the association of childhood adversities with PTSD wanes later in life because of increased temporal distance from the childhood adversity, variations in the features of traumatic events across the lifespan, or protective factors that increase in later life. Alternatively, it might reflect recall biases in childhood adversity reports that are strongest among older adults, where the recall interval is longest. PTSD is associated with overgeneral autobiographical memory, ${ }^{40}$ and it is possible that this effect is more pronounced in older adults. Underreporting of childhood adversities would attenuate childhood adversity-PTSD associations in the oldest group if PTSD symptoms are not underreported. The fact that childhood adversities were negatively associated with PTSD among older adults might be because of selection of especially resilient individuals with childhood adversity histories into the later years of life.

\section{Interpretation of our findings}

Why might exposure to child maltreatment and parent psychopathology influence vulnerability to PTSD? And why were only these specific MFF childhood adversities associated with PTSD? One potential mechanism involves heightened salience of threat cues and magnified emotional reactions to potential threats. Child maltreatment is associated with elevated emotional reactivity to negative stimuli, as measured using self-report, ${ }^{41,42}$ ecological momentary assessments of daily responses to stressful life events, ${ }^{43}$ and amygdala response to negative stimuli. ${ }^{44-47}$ Similar patterns have been observed in children of parents with psychopathology. ${ }^{48,49}$ Heightened amygdala reactivity to threat may be a key pathway through which maltreatment and parent psychopathology influence later risk for PTSD. Prospective studies in both adolescents and military samples have shown that elevated amygdala response to threat cues assessed prior to trauma exposure predicts the subsequent onset of PTSD symptoms following a traumatic event. ${ }^{50,51}$ Amygdala reactivity to threat cues decreases in older age, ${ }^{52}$ which may have contributed to the lack of childhood adversity-PTSD associations in older adults, although this does not account for the negative childhood adversity-PTSD association among older respondents. The specificity of this pattern of neural response to childhood adversities involving direct exposure to threat ${ }^{53}$ or parent psychopathology ${ }^{46,47}$ may explain, in part, why childhood adversities involving interpersonal loss and economic adversity were not associated with PTSD vulnerability. Other mechanisms are also likely to play a role in the associations of these specific MFF childhood adversities with PTSD, including habitual use of maladaptive emotion regulation strategies (such as rumination) and low social support, each of which is associated with child maltreatment and parent psychopathology as well as risk for PTSD..$^{1,41,54-56}$

\section{Limitations}

This study is limited by retrospective reports of childhood adversities, trauma exposure and PTSD symptoms. Recall bias of childhood adversities primarily involves underreporting, ${ }^{57-59}$ which likely attenuated associations of childhood adversities with 
PTSD. The absence of childhood adversity associations with PTSD in the oldest respondents could reflect underreporting that was most pronounced among respondents with the longest recall periods. ${ }^{15}$ Additionally, assessment of PTSD with a fully structured diagnostic interview rather than clinician-administered interview likely introduced imprecision. The CIDI diagnoses were relatively conservative, meaning that low-severity cases of PTSD may have been missed. We did not assess all relevant childhood adversities, most notably emotional abuse. Determining whether emotional abuse influences vulnerability to PTSD in a similar manner as physical and sexual abuse is an important direction for future work. Finally, our measure of economic adversity included assessment of receipt of governmental assistance, which varies widely across countries in terms of availability and eligibility criteria and may underestimate economic adversity in some countries.

Despite these limitations, we replicate prior work indicating that child maltreatment is associated with heightened vulnerability to PTSD following traumatic events occurring later in development. We extend earlier findings by showing that a similar association exists with regard to parent psychopathology but not other forms of childhood adversity, that the association of childhood adversities involving child maltreatment and parent psychopathology with PTSD are additive and do not vary across trauma types, and that childhood adversity-PTSD associations are limited to childhood, adolescence and early-middle adulthood. These results build on a growing body of evidence indicating that early experiences of adversity increase vulnerability to psychopathology following stressors later in development and suggest that childhood adversities involving child maltreatment and parental psychopathology are associated with heightened risk for PTSD following a traumatic event.

\section{Funding}

The World Health Organization (WHO) World Mental Health (WMH) Survey Initiative is supported by the National Institute of Mental Health (NIMH); R01 MH070884 and RO1 MH093612-01), the John D. and Catherine T. MacArthur Foundation, the Pfizer Foundation, the US Public Health Service (R13-MH066849, R01-MH069864, and R01 DA016558), the the US Public Health Service (R13-MH066849, R01-MH069864, and R01 DA016558), the (PAHO), Eli Lilly and Company, Ortho-McNeil Pharmaceutical, Inc., GlaxoSmithKline, and Bristol-Myers Squibb. R.C.K. and K.C.K. were supported by the US NIMH under Award Number R01MH101227. The São Paulo Megacity Mental Health Survey is supported by the State of São Paulo Research Foundation (FAPESP) Thematic Project Grant 03/00204-3. The Bulgarian Epidemiological Study of common mental disorders, EPIBUL, is supported by the Ministry of Health and the National Center for Public Health Protection. The Colombian the Ministry of Health and the National Center for Public Health Protection. The Colombian
National Study of Mental Health (NSMH) is supported by the Ministry of Social Protection. The Mental Health Study Medellín - Colombia was carried out and supported jointly by the Center for Excellence on Research in Mental Health (CES University) and the Secretary of Health of Medellín. The ESEMeD project is funded by the European Commission (Contracts QLG5-1999-01042; SANCO 2004123, and EAHC 20081308), (the Piedmont Region (Italy)) Fondo de Investigación Sanitaria, Instituto de Salud Carlos III, Spain (FIS 00/0028), Ministerio de Ciencia y Tecnología, Spain (SAF 2000-158-CE), Departament de Salut, Generalitat de Catalunya, Spain, Instituto de Salud Carlos III (CIBER CB06/02/0046, RETICS RD06/0011 REM-TAP), and other local agencies and by an unrestricted educational gran from GlaxoSmithKline. The World Mental Health Japan (WMHJ) Survey is supported by the Grant for Research on Psychiatric and Neurological Diseases and Mental Health (H13-SHOGAI-023, H14-TOKUBETSU-026, H16-KOKORO-013, H25-SEISHIN-IPPAN-006) from the Japan Ministry of Health, Labour and Welfare. The Lebanese Evaluation of the Burden of Ailments and Needs of the Nation (L.E.B.A.N.O.N.) is supported by the Lebanese Ministry of Public Health, the WHO (Lebanon), National Institute of Health/Fogarty International Center (RO3 TW006481-01), anonymous private donations to IDRAAC, Lebanon, and unrestricted grants from, Algorithm, AstraZeneca, Benta, Bella Pharma, Eli Lilly, GlaxoSmithKline, Lundbeck Novartis, Servier, Phenicia, UPO. The Mexican National Comorbidity Survey (MNCS) is supported by The National Institute of Psychiatry Ramon de la Fuente (INPRFMDIES 4280) and by the National Council on Science and Technology (CONACYT-G30544-H), with supplemental support from the PAHO. The Northern Ireland Study of Mental Health was funded by the Health \& Social Care Research \& Development Division of the Public Health Agency. The Peruvian WMH Study was funded by the National Institute of Health of the Ministry of Health of Peru. The Romania WMH study projects 'Policies in Mental Healt Area' and 'National Study regarding Mental Health and Services Use' were carried out by National School of Public Health \& Health Services Management (former Nationa Institute for Research \& Development in Health), with technical support of Metro Media Transilvania, the National Instit Transivania, the National Institute of Statistics-National Centre for Training in Statistics, SC, Cheyenne Services SRL, Statistics Netherlands and were funded by Ministry of Public Health (former Ministry of Health) with supplemental support of Eli Lilly
Romania, SRL. The South Africa Stress and Health Study (SASH) is supported by the US
NIMH (R01-MH059575) and National Institute of Drug Abuse (NIDA) with supplemental funding from the South African Department of Health and the University of Michigan. D.J.S is supported by the Medical Research Council of South Africa (MRC). The Psychiatric Enquiry to General Population in Southeast Spain - Murcia (PEGASUS-Murcia) Project has been financed by the Regional Health Authorities of Murcia (Servicio Murciano de Salud and Consejería de Sanidad y Política Social) and Fundación para la Formación e Investigación Sanitarias (FFIS) of Murcia. The Ukraine Comorbid Mental Disorders during periods of Social Disruption (CMDPSD) study is funded by the US NIMH (RO1-MH61905). The US National Comorbidity Survey Replication (NCS-R) is supported by the NIMH (U01MH60220) with supplemental support from the NIDA, the substance Abuse and Mental Health Services Administration (SAMHSA), the Robert Wood Johnson Foundation (Grant 044708), and the John W. Alden Trust. None of the funders had any role in the design, analysis, interpretation of results, or preparation of this paper. The views and opinions expressed in this report are those of the authors and should not be construed to represent the views of the WHO, other sponsoring organisations, agencies, or governments.

Katie A. McLaughlin, PhD, Department of Psychology, University of Washington, Seattle, Washington, USA; Karestan C. Koenen, PhD, Department of Epidemiology,
Harvard T.H. Chan School of Public Health, Boston, Massachusetts, USA; Evelyn J. Bromet, PhD, Department of Psychiatry, Stony Brook University School of Medicine, Stony Brook, New York, USA; Elie G. Karam, MD, Department of Psychiatry and Clinical Psychology, Faculty of Medicine, Balamand University, Beirut, Department of Psychiatry and Clinical Psychology, St George Hospital University Medical Center, Beirut and Institute for Development Research Advocacy and Applied Care (IDRAAC) Beirut, Lebanon; Howard Liu, SM, Maria Petukhova, PhD, Department of Health Care Policy, Harvard Medical School, Boston, Massachusetts, USA; Ayelet Meron Ruscio, PhD, Department of Psychology, University of Pennsylvania, Philadelphia, Pennsylvania, USA; Nancy A. Sampson, BA, Department of Health Care Policy, Harvard Medical School, Boston, Massachusetts, USA; Dan J. Stein, FRCPC, PhD, Department of Psychiatry and Mental Health, University of Cape Town, Cape Town, Republic of South Africa; Sergio Aguilar-Gaxiola, MD, PhD, Center for Reducing Health Disparities, UC Davis Health System, Sacramento, California, USA; Jordi Alonso, MD, DrPH, IMIM-Hospital del Mar Research Institute, Parc de Salut Mar, Barcelona, Pompeu Fabra University (UPF), Barcelona and CIBER en Epidemiología y Salud Pública (CIBERESP), Barcelona, Spain; Guilherme Borges, DrSc, Instituto Nacional de Psiquiatría, San Lorenzo Huipulco, Mexico; Koen Demyttenaere, MD, PhD, Department of Psychiatry, University Hospital Gasthuisberg, Katholieke Universiteit Leuven, Leuven, Belgium; Rumyana V. Dinolova, MD, National Center of Public Health and Analyses, Sofia, Bulgaria; Finola Ferry, PhD, Bamford Centre for Mental Health and Wellbeing, Ulster University, Coleraine, UK; Silvia Florescu, MD, PhD, National School of Public Health, Management and Development, Bucharest, Romania; Giovanni de Girolamo, MD, Unit of Epidemiological and Evaluation Psychiatry, IRCCS-St. John of God Clinical Research Centre, Brescia, Italy; Oye Gureje, MD, PhD, FRCPsych, Department of Psychiatry, University College Hospital, Ibadan, Nigeria; Norito Kawakami, MD, DMSc, Department of Mental Health, School of Public Health, The University of Tokyo, Tokyo, Japan; Sing Lee, MB, BS, Department of Psychiatry, Chinese University of Hong Kong, Tai PO, Hong Kong; Fernando Navarro-Mateu, MD, PhD, UDIF-SM, Subdirección General de Planificación, Innovación y Cronicidad, Servicio Murciano de Salud, Murcia, IMIBArrixaca, Murcia and CIBERESP-Murcia, Murcia, Spain; Marina Piazza, SCD, MPH, Universidad Cayetano Heredia; National Institute of Health, Lima, Peru; Beth-Ellen Pennell, MA, Survey Research Center, Institute for Social Research, University of Michigan, Ann Arbor, Michigan, USA J José Posada-Villa, MD, Faculty of Social Sciences Colegio Mayor de Cundinamarca University, Bogota, Colombia; Margreet Sciences Colegio Mayor de Cundinamarca University, Bogota, Colombia; Marg
ten Have, PhD, Trimbos-Instituut, Netherlands Institute of Mental Health and Addiction, Utrecht, The Netherlands; Maria Carmen Viana, MD, PhD, Department of Social Medicine, Federal University of Espírito Santo, Vitoria, Brazil; Ronald C. Kessler, PhD, Department of Health Care Policy, Harvard Medical School, Boston, Massachusetts, USA

Correspondence: Katie A. McLaughlin, Department of Psychology, University of Washington, Box 351525, Seattle, WA 98195, USA. Email: mclaughk@uw.edu

First received 20 Dec 2016, final revision 22 May 2017, accepted 24 May 2017

\section{Acknowledgements}

We thank the staff of the WMH Data Collection and Data Analysis Coordination Centres for assistance with instrumentation, fieldwork, and consultation on data analysis. A complete list of all within-country and cross-national WMH publications can be found at: http:// www.hcp.med.harvard.edu/wmh/

\section{Appendix}

The paper is submitted on behalf of the World Health Organization World Mental Health Survey collaborators: Sergio Aguilar-Gaxiola, MD, PhD, Ali Al-Hamzawi, MD, Mohammed Salih Al-Kaisy, MD, Jordi Alonso, MD, DrPH, Laura Helena Andrade, MD, PhD, Corina Benjet, PhD, Guilherme Borges, SCD, Evelyn J. Bromet, PhD, Ronny Bruffaerts, PhD, Brendan Bunting, PhD, Jose Miguel Caldas de Almeida, MD, PhD, Graca Cardoso, MD, PhD, Somnath Chatterji, MD, Alfredo H. Cia, MD, Louisa Degenhardt, $\mathrm{PhD}$, Koen Demyttenaere, MD, PhD, John Fayyad, MD, Silvia Florescu, $\mathrm{MD}$, PhD, Giovanni de Girolamo, MD, Oye Gureje, PhD, DSc, FRCPsych, Josep Maria Haro, MD, PhD, Yanling He, MD, Hristo Hinkov, MD, Chi-yi $\mathrm{Hu}, \mathrm{PhD}, \mathrm{MD}$, Yueqin Huang, MD, MPH, Peter de Jonge, PhD, Aimee 
Nasser Karam, PhD, Elie G. Karam, MD, Norito Kawakami, MD, DMSc, Ronald C. Kessler, PhD, Andrzej Kiejna, MD, PhD, Viviane Kovess-Masfety, $M D$, PhD, sing Lee, MB, BS, Jean-Pierre Lepine, MD, Daphna Levinson, $\mathrm{PhD}$, John McGrath, MD, PhD, Maria Elena Medina-Mora, PhD, Jacek Moskalewicz, DrPH, Fernando Navarro-Mateu, MD, PhD, Beth-Ellen Pennell, MA, Marina Piazza, MPH, SCD, Jose Posada-Villa, MD, Kate M. Scott, PhD, Tim Slade, PhD, Juan Carlos Stagnaro, MD, PhD, Dan J. Stein, FRCPC, PhD, Margreet ten Have, PhD, Yolanda Torres, MPH, Dra.HC, Maria Carmen Viana, MD, PhD, Harvey Whiteford, PhD, David R.Williams, $\mathrm{MPH}, \mathrm{PhD}$ and Bogdan Wojtyniak, SCD.

\section{References}

1 Brewin CR, Andrews B, Valentine JD. Meta-analysis of risk factors for posttraumatic stress disorder in trauma-exposed adults. J Consult Clin Psychol 2000; 68: 748-66.

2 Koenen KC, Moffit TE, Poulin R, Martin J, Caspi A. Early childhood factors associated with the development of post-traumatic stress disorder: results from a longitudinal birth cohort. Psychol Med 2007; 37: 181-92.

3 Scott KM, Smith DR, Ellis PM. Prospectively ascertained childhood maltreatment and its associations with DSM-IV mental disorders in young adults. Arch Gen Psychiatry 2010; 67: 712-9.

4 Bremmer JD, Southwick SM, Johnson DR, Yehuda R, Charney DS. Childhood physical abuse and combat-related posttraumatic stress disorder in Vietnam veterans. Am J Psychiatry 1993; 150: 235-9.

5 Schnurr PP, Lunney CA, Sengupta A. Risk factors for the development versus maintenance of posttraumatic stress disorder. J Trauma Stress 2004; 17: 85-95.

6 McLaughlin KA, Conron KJ, Koenen KC, Gilman SE. Childhood adversity, adult stressful life events, and risk of past-year psychiatric disorder: a test of the stress sensitization hypothesis in a population-based sample of adults. Psychol Med 2010; 40: 1647-58.

7 Myers B, McLaughlin KA, Wang S, Blanco C, Stein DJ. Associations between childhood adversity, adult stressful life events, and past-year drug use disorders in the National Epidemiological Study of Alcohol and Related Conditions (NESARC). Psychol Addict Behav 2014; 28: 1117-26.

8 Roberts AL, McLaughlin KA, Conron KJ, Koenen KC. Adult stressors, history of childhood adversity, and risk of perpetration of intimate partner violence among men and women. Am J Prevent Med 2010; 40: 128-38.

9 Keyes KM, Shmulewitz D, Greenstein E, McLaughlin KA, Wall M, Aharonovich $\mathrm{E}$, et al. Exposure to the Lebanon War of 2006 and effects on alcohol use disorders: the moderating role of childhood maltreatment. Drug Alcohol Depend 2014; 134: 296-303.

10 Hammen C, Henry R, Daley SE. Depression and sensitization to stressors among young women as a function of childhood adversity. $J$ Consult Clin Psychol 2000; 68: 782-7.

11 Harkness KL, Bruce AE, Lumley MN. The role of childhood abuse and neglect in the sensitization to stressful life events in adolescent depression. J Abnorm Psychol 2006; 115: 730-41.

12 Espejo EP, Hammen C, Connolly NP, Brennan PA, Najman JM, Bor W. Stress sensitization and adolescent depressive severity as a function of childhood adversity: a link to anxiety disorders. J Abnorm Child Psychol 2006; 35 287-99.

13 Kessler RC, Davis CG, Kendler KS. Childhood adversity and adult psychiatric disorder in the US National Comorbidity Survey. Psychol Med 1997; 27 1101-19.

14 Kessler RC, McLaughlin KA, Green JG, Gruber MJ, Sampson NA, Zaslavsky $\mathrm{AM}$, et al. Childhood adversities and adult psychopathology in the WHO World Mental Health Surveys. Br J Psychiatry 2010; 197: 378-85

15 Green JG, McLaughlin KA, Berglund P, Gruber MJ, Sampson NA, Zaslavsky AM, et al. Childhood adversities and adult psychopathology in the National Comorbidity Survey Replication (NCS-R) I: associations with first onset of DSM-IV disorders. Arch Gen Psychiatry 2010; 62: 113-23.

16 McLaughlin KA, Green JG, Gruber MJ, Sampson NA, Zaslavsky A, Kessler RC. Childhood adversities and first onset of psychiatric disorders in a national sample of adolescents. Arch Gen Psychiatry 2012; 69: 1151-60.

17 Breslau N, Kessler RC, Chilcoat HD, Schultz LR, Davis GC, Andreski P. Trauma and posttraumatic stress disorder in the community: the 1996 Detroit Area Survey of Trauma. Arch Gen Psychiatry 1998; 55: 626-32.

18 Kessler RC, Sonnega A, Bromet E, Hughes M, Nelson CB. Posttraumatic stress disorder in the National Comorbidity Survey. Arch Gen Psychiatry 1995; 52: 1048-60.

19 Liu H, Petukhova M, Sampson NA, Aguilar-Gaxiola S, Alonso J, Andrade LH et al. Association of DSM-IV post-traumatic stress disorder with traumatic experience type and history in the World Health Organization World Mental Health Surveys. JAMA Psychiatry 2017; 74: 270-81.

20 The World Bank. Data: Countries and Economies. The World Bank Group, 2016

21 Heeringa SG, Wells EJ, Hubbard F, Mneimneh ZN, Chiu WT, Sampson NA, et al. Sample designs and sampling procedures. In The WHO World Mental Health Surveys: Global Perspectives on the Epidemiology of Mental Disorders (eds RC Kessler, TB Üstun): 14-32. Cambridge University Press, 2008

22 Harkness J, Pennell B-P, Villar A, Gebler N, Aguilar-Gaxiola S, Bilgen I. Translation procedures and translation assessment in the World Mental Health Survey Initiative. In The WHO World Mental Health Surveys: Global Perspectives on the Epidemiology of Mental Disorders (eds RC Kessler, TB Üstun): 91-113. Cambridge University Press, 2008.

23 American Psychiatric Association. Diagnostic and Statistical Manual of Mental Disorders (4th edn) (DSM-IV). APA, 1994.

24 Benjet C, Bromet E, Karam EG, Kessler RC, McLaughlin KA, Ruscio AM, et al. The epidemiology of traumatic event exposure worldwide: results from the World Mental Health Survey Consortium. Psychol Med 2016; 46: 327-43.

25 Kessler RC, Üstun TB. The World Mental Health (WHM) Survey Initiative Version of the World Health Organization (WHO) Composite Internationa Diagnostic Interview (CIDI). Int J Methods Psychiatr Res 2004; 13: 93-121.

26 McLaughlin KA, Koenen KC, Friedman MJ, Ruscio AM, Karam EG, Shahly V, et al. Subthreshold posttraumatic stress disorder in the World Health Organization World Mental Health Surveys. Biol Psychiatry 2015; 77: 375-84

27 Haro JM, Arbabzadeh-Bouchez S, Brugha TS, di Girolamo G, Guyer M, Jin R, et al. Concordance of the Composite International Diagnostic Interview Version 3.0 (CIDI 3.0) with standardized clinical assessments in the WHO World Mental Health Surveys. Int J Methods Psychiatr Res 2006; 15: 167-80.

28 Gardner M, Altman D. Statistics with Confidence: Confidence Intervals and Statistical Guidelines. BMJ Books, 2000.

29 Felitti VJ, Anda RF, Nordenberg D, Williamson DF, Spitz AM, Edwards V, et al. Relationship of childhood abuse and household dysfunction to many of the leading causes of death in adults: the Adverse Childhood Experiences (ACE) Study. Am J Prevent Med 1998; 14: 245-58.

30 Straus MA. Measuring intrafamily conflict and violence: the Conflict Tactics (CT) Scales. J Marriage Fam 1979; 41: 75-88

31 Courtney ME, Piliavin I, Grogan-Kaylor A, Nesmith A. Foster Youth Transitions to Adulthood: A Longitudinal View of Youth Leaving Care. Institute for Research on Poverty, 1998.

32 Endicott J, Andreasen N, Spitzer RL. Family History Research Diagnostic Criteria. Biometrics Research, NY State Psychiatric Institute, 1978.

33 Kendler KS, Silberg JL, Neale MC, Kessler RC, Heath AC, Eaves L. The family history method: whose psychiatric history is measured? Am J Psychiatry 1991; 148: 1501-4.

34 Klebanoff MA, Cole SR. Use of multiple imputatio in the epidemiologic literature. Am J Epidemiol 2008; 168: 355-7.

35 Wolter KM. Introduction to Variance Estimation. Springer-Verlag, 1985.

36 McLaughlin KA, Gadermann AM, Hwang I, Sampson NA, Al-Hamzawi A, Andrade $\mathrm{LH}$, et al. Parent psychopathology and offspring mental disorders: results from the WHO World Mental Health Surveys. Br J Psychiatry 2012; 200: $290-9$.

37 Caspi A, Houts RM, Belsky DW, Goldman-Mellor SJ, Harrington H, Israel S, et al. The $\mathrm{p}$ factor: one general psychopathology factor in the structure of psychiatric disorders? Clin Psychol Sci 2014; 2: 119-37.

38 Rudolph KD, Flynn M. Childhood adversity and youth depression: influence of gender and pubertal status. Develop Psychopathol 2007; 19: 497-521.

39 Breslau N, Koenen KC, Luo Z, Agnew-Blais J, Swanson S, Houts RM, et al. Childhood maltreatment, juvenile disorders and adult post-traumatic stress disorder: a prospective investigation. Psychol Med 2014; 44: 1937-45.

40 Moore SA, Zoellner LA. Overgeneral autobiolographical memory and traumatic events: an evaluative review. Psychol Bull 2007; 133: 419-37.

41 Heleniak C, Jenness J, Van der Stoep A, McCauley E, McLaughlin KA. Childhood maltreatment exposure and disruptions in emotion regulation: a transdiagnostic pathway to adolescent internalizing and externalizing psychopathology. Cogn Ther Res 2016; 40: 394-415.

42 Hennessy KD, Rabideau GJ, Cicchetti D, Cummings EM. Responses of physically abused and nonabused children to different forms of interadult anger. Child Develop 1994; 65: 815-28.

43 Wichers M, Schrijvers D, Geschwind N, Jacobs N, Myin-Germeys I, Thiery E, et al. Mechanisms of gene-environment interactions in depression: evidence that genes potentiate multiple sources of adversity. Psychol Med 2009; 39: 1077-86.

44 McCrory EJ, De Brito SA, Kelly PA, Bird G, Sebastian CL, Mechelli A, et al. Amygdala activation in maltreated children during pre-attentive emotional processing. Br J Psychiatry 2013; 202: 269-76. 
45 Mccrory EJ, De Brito SA, Sebastian CL, Mechelli A, Bird G, Kelly PA, et al. Heightened neural reactivity to threat in child victims of family violence. Curr Biol 2011; 21: R947-8.

46 Suzuki H, Luby JL, Botteron KN, Dietrich R, McAvoy MP, Barch DM. Early life stress and trauma and enhanced limbic activation to emotionally valenced faces in depressed and healthy children. J Am Acad Child Adolesc Psychiatry 2014; 53: 800-13

47 McLaughlin KA, Peverill M, Gold AL, Alves S, Sheridan MA. Child maltreatment and neural systems underlying emotion regulation. J Am Acad Child Adolesc Psychiatry 2015; 54: 753-62.

48 Feldman R, Granat A, Pariente C, Kanety H, Kuint J, Gilboa-Schechtman E. Maternal depression and anxiety across the postpartum year and infant social engagement, fear regulation, and stress reactivity. J Am Acad Child Adolesc Psychiatry 2009; 48: 919-27.

49 Davis EP, Glynn LM, Schetter CD, Hobel C, Chicz-Demet A, Sandman CA. Prenatal exposure to maternal depression and cortisol influences infant temperament. Am Acad Child Adolesc Psychiatry 2007; 46: 737-46.

50 McLaughlin KA, Busso DS, Duys A, Green JG, Alves S, Way M, et al. Amygdala response to negative stimuli predicts PTSD symptom onset following a terrorist attack. Depress Anxiety 2014; 10: 834-42.

51 Admon R, Lubin G, Stern O, Rosenberg K, Sela L, Ben-Ami H, et al. Human vulnerability to stress depends on amygdala's predisposition and hippocampal plasticity. Proc Natl Acad Sci 2009; 106: 14120-5.
52 Mather $M$, Canli T, English T, Whitfield $S$, Wais $P$, Ochsner $K$, et al Amygdala responses to emotionally valenced stimuli in older and younger adults. Psychol Sci 2004; 15: 259-63.

53 McLaughlin KA, Sheridan MA, Lambert HK. Childhood adversity and neura development: deprivation and threat as distinct dimensions of early experience. Neurosci Biobehav Rev 2014; 47: 578-91.

54 Jenness J, Jager-Hyman S, Heleniak C, Beck AT, Sheridan MA, McLaughlin KA. Catastrophizing, rumination, and reappraisal prospectively predict adolescent PTSD symptom onset following a terrorist attack. Depress Anxiety 2016; Aug 24 (Epub ahead of print).

55 Kuyken W, Watkins $\mathrm{E}$, Holden $\mathrm{E}$, Cook W. Rumination in adolescents at risk for depression. J Affect Disord 2006; 96: 39-47.

56 Sheikh MA, Abelsen B, Olsen JA. Clarifying associations between childhood adversity, social support, behavioral factors, and mental health, health, and well-being in adulthood: a population-based study. Front Psychol 2016; 7 727.

57 Hardt J, Rutter M. Validity of adult retrospective reports of adverse childhood experiences: review of the evidence. J Child Psychol Psychiatry 2004; 45 260-73

58 Widom CS, Shepard RL. Accuracy of adult recollections of childhood victimization: Part 1. Childhood physical abuse. Psychol Assess 1996; 8 : 412-21.

59 Widom CS, Morris S. Accuracy of adult recollections of childhood victimization: Part 2. Childhood sexual abuse. Psychol Assess 1997; 9: 34-46.

\section{psychiatry in history}

\section{'A Week Before Examination' by Lucretia Maria Davidson (1808-1825)}

\section{Oyedeji Ayonrinde}

The poem, written nearly 200 years ago by a New York teenager, has lost none of its currency today. 'Exam stress', fear of failure, burden of expectation and exam-related somatic and emotional complaints are also features of modern education. Lucretia's distress was genuine: 'Oh, how I dread it! But there is no retreat [ . . . ] We must study morning, noon and night. I shal rise between two and four now every morning, till the dreaded day is past...'. To relieve her 'examination fever', her doctor carried out bloodletting and induced vomiting. This sort of treatment, at least, is a thing of the past.

One has a headache, one a cold,

One has her neck in flannel rolled:

Ask the complaint, and you are told

'Next week's examination.'

One frets and scolds, and laughs and cries,

Another hopes, despairs, and sighs;

Ask but the cause, and each replies,

'Next week's examination.'

One bans her books, then grasps them tight,

And studies morning, noon, and night,

As though she took some strange delight

'In these examinations.'

The books are marked, defaced, and thumbed,

The brains with midnight tasks benumbed,

Still all in that account is summed,

'Next week's examination.'

From Poems by Lucretia Maria Davidson (edited by Oliver Davidson, 1871). 